\title{
Determination of Predictive Risk Factors for Severe Bronchiolitis
}

\author{
Muhammed Nebi Caliskan ${ }^{1}$, Mehmet Tekin ${ }^{2}$, and Çapan KONCA ${ }^{1}$ \\ ${ }^{1}$ Adiyaman Universitesi Tip Fakultesi \\ ${ }^{2}$ Inonu Universitesi Tip fakultesi
}

February 5, 2021

\begin{abstract}
Background: The aim of this study was to determine the predictive risk factors for development of severe bronchiolitis in patients with acute bronchiolitis with no previous chronic disease. Methods: Four hundred forty children aged 1-24 months hospitalized with acute bronchiolitis, were examined between February 2018 and February 2019 in this prospective study. Results: Eightyfive cases were regarded as severe bronchiolitis and 355 as mild-moderate bronchiolitis. Statistically significant differences were observed between the severe and mild-moderate bronchiolitis groups in terms of weight-for-age z-scores, history of bronchiolitis, hemoglobin levels, and time elapsed between onset of symptoms and admission. Weight-for-age z-scores, the mean time interval between onset of symptoms and admission, and mean hemoglobin values were lower in the severe bronchiolitis group while the mean number of bronchiolitis attacks was higher than in the mild-moderate bronchiolitis group. Logistic regression analysis determined that a low weight-for-age z-score increased the risk of severe bronchiolitis development 0.56-fold (CI: 0.409 - 0.760), a short duration between the onset of symptoms and admission increased the risk 0.62-fold (CI: 0.519 - 0.735), a frequent history of bronchiolitis increased the risk 1.81-fold (CI: 1.135 - 2.968) and low hemoglobin levels increased the risk 0.72-fold (CI: 0.537 - 0.969). Conclusion: Low weight-for-age z-scores, a short duration between the onset of symptoms and admission, a high number of previous attacks, and low hemoglobin levels were identified as independent parameters of severe bronchiolitis development. Key words: Bronchiolitis, Infant, Risk factors, Severity degree
\end{abstract}

\section{Determination of Predictive Risk Factors for Severe Bronchiolitis}

\section{Abstract}

Background: The aim of this study was to determine the predictive risk factors for development of severe bronchiolitis in patients with acute bronchiolitis with no previous chronic disease.

Methods: Four hundred forty children aged 1-24 months hospitalized with acute bronchiolitis, were examined between February 2018 and February 2019 in this prospective study.

Results: Eighty-five cases were regarded as severe bronchiolitis and 355 as mild-moderate bronchiolitis. Statistically significant differences were observed between the severe and mild-moderate bronchiolitis groups in terms of weight-for-age z-scores, history of bronchiolitis, hemoglobin levels, and time elapsed between onset of symptoms and admission. Weight-for-age z-scores, the mean time interval between onset of symptoms and admission, and mean hemoglobin values were lower in the severe bronchiolitis group while the mean number of bronchiolitis attacks was higher than in the mild-moderate bronchiolitis group. Logistic regression analysis determined that a low weight-for-age z-score increased the risk of severe bronchiolitis development 0.56 -fold (CI: $0.409-0.760$ ), a short duration between the onset of symptoms and admission increased the risk 0.62 -fold (CI: $0.519-0.735$ ), a frequent history of bronchiolitis increased the risk 1.81-fold (CI: 1.135 2.968 ) and low hemoglobin levels increased the risk 0.72-fold (CI: $0.537-0.969$ ).

Conclusion: Low weight-for-age z-scores, a short duration between the onset of symptoms and admission, a high number of previous attacks, and low hemoglobin levels were identified as independent parameters of 
severe bronchiolitis development.

Key words: Bronchiolitis, Infant, Risk factors, Severity degree

\section{What's known}

- Acute bronchiolitis is a lower airway disease frequently seen in children under the age of two years.

- The course of the disease is severe in some patients.

- There are studies in the literature examining the relationship between severe bronchiolitis and various personal, familial, and environmental risk factors. However, predictive risk factors for severe bronchiolitis have not been identified.

\section{What's new}

We observed a higher risk of severe bronchiolitis development in individuals with a low weight-for-age z-score, with a short time elapsing between onset of symptoms and admission, with a larger number of previous attacks, and with low hemoglobin.

\section{Introduction}

Acute bronchiolitis is a lower airway disease frequently seen in children under the age of two years and generally characterized by inflammation of the small airways caused by viral agents. Onset occurs with upper airway infection findings such as cough and nasal discharge, followed by wheeze, prolonged expiration, rapid breathing, and retractions in the chest. ${ }^{1,2}$ Rapid respiration, retractions caused by the functioning of the accessory respiratory muscles, and low oxygen saturation are evaluated as severe disease findings. ${ }^{1}$

Acute bronchiolitis is more common in boys, in children who are not breastfed, in those exposed to cigarette smoke, and in the children of families of low socioeconomic status. ${ }^{2}$ The course of the disease is severe in some patients, and may require hospitalization and intensive care. Children with histories of premature birth, babies younger than three months, and patients with cardiovascular, neurological, or pulmonary diseases and immune deficiency are at risk of developing acute bronchiolitis. ${ }^{1,2}$ Living under crowded conditions and the presence of siblings have also been described as risk factors for development of severe bronchiolitis. ${ }^{3,4}$ Since maternal smoking during pregnancy increases hospitalization rates and results in a severe course of disease in patients with bronchiolitis, respiratory support with mechanical ventilation may be required. ${ }^{5,6}$ A history of airway disease in the perinatal and neonatal period has been reported to increase the risk of bronchiolitis and hospitalization. ${ }^{4}$ It has also been suggested that genetic factors may affect a severe disease course. ${ }^{7}$

Identifying factors increasing the risk of acute bronchiolitis development in patients with no chronic disease is important in terms of standardizing the frequency of follow-ups and hospitalization indications in bronchiolitis patients, and in terms of deciding to intervene early in case of at-risk patients. The purpose of the present study was to determine predictive individual, familial, and environmental risk factors for development of severe bronchiolitis in healthy-appearing acute bronchiolitis patients with no previous history of chronic disease.

\section{Materials and Methods}

Four hundred forty children aged 1-24 months hospitalized with diagnoses of acute bronchiolitis between February 2018 and February 2019 were included in this prospective study. The study was designed in compliance with the principles of the Declaration of Helsinki, and approval was granted by the Clinical Research Ethical Committee (No. 2018/1-6 dated 23.01.2018). Informed consent forms were obtained from individuals legally responsible for the care of the patients included in the study.

Patients younger than one or older than 24 months, or with histories of congenital heart disease, neuromuscular disease, immunodeficiency, chronic lung disease (such as cystic fibrosis or bronchopulmonary dysplasia), metabolic disease, or sibling death were excluded from the study.

Marked retractions resulting from the functioning of the accessory respiratory muscles, an increased respiration rate, and oxygen saturation of $90 \%$ or less were regarded as severe bronchiolitis. ${ }^{1}$ Weight-for-age z-score 
values of +2.00 or above were regarded as obesity, values between -1.00 and -1.99 as mild malnutrition, scores between -2.00 and -2.99 as moderate malnutrition, and values of -3.00 or below as severe malnutrition.

The age, sex, weight, and weight-for-age z-score of patients hospitalized to the infant ward were recorded. Weight-for-age z-scores were calculated using the World Health Organizations (WHO) Anthro software. The presentation symptom, time of onset, and time elapsed between onset and worsening of symptoms were subsequently investigated. Data concerning type of delivery and gestational week, type of feeding (mother's milk only, mother's milk plus formula, or formula only), presence of atopy/food allergy, previous history of bronchiolitis, history of admission to the neonatal intensive care unit (NICU), and presence of gastroesophageal reflux disease (GERD) were also recorded. Parental history of asthma, history of maternal smoking during pregnancy, history of smoking in the home, parental education levels, number of siblings, and number of individuals in the household were also noted. Characteristics of the place of residence (rural area or urban, type of heating, and type of accommodation) were investigated in the environmental history. The patient's physical examination findings, type of feeding during the disease, oxygen requirements, bronchiolitis clinical status, methods providing oxygen support (mask, high-flow nasal cannula (HFNC), or intubation), and data concerning treatment were recorded. Laboratory parameter findings such as white blood cell (WBC) count, hemoglobin (Hb), platelet count, absolute neutrophil count (ANC), lymphocyte count, serum C-reactive protein $(\mathrm{CRP})$, and blood gas values $(\mathrm{pH}$, partial carbon dioxide pressure ( $\mathrm{pCO} 2)$, partial oxygen pressure (pO2) and bicarbonate (HCO3)) were also recorded.

\section{Statistical Analyses}

Data were analyzed on Statistical Package for Social Sciences Statistical Software, version 23.0 (SPSS Inc., Chicago, IL, USA). Descriptive statistics were produced. Data were expressed as number (percentage) or mean \pm standard deviation (minimum-maximum). Categorical data were compared using the chi-square and Fisher's exact tests. The Kolmogorov-Smirnov test was applied to determine whether continuous data were normally distributed. Normally distributed data were expressed as mean \pm standard deviation (minimummaximum) and were compared using the independent two sample t test. $\mathrm{p}$ values $<0.05$ were regarded as statistically significant.

Single variable logistic regression analysis was applied to identify independent predictors of severe bronchiolitis development, and the parameters determined were then subjected to multivariate logistic regression analysis (backward LR model).

\section{Results}

Four hundred seventy-one patients hospitalized with diagnoses of acute bronchiolitis were initially included in the study. However, 31 patients were subsequently excluded, 16 diagnosed with congenital heart disease, four with metabolic disease, three with histories of sibling deaths, and eight whose families declined to take part. Four hundred forty patients aged between one and 24 months were thus finally enrolled.

Two hundred seventy-seven $(63 \%)$ of the 440 patients were boys, and $163(37 \%)$ were girls. The mean age of the patients was $6.16 \pm 4.99$ months. Patients were divided into two groups, severe bronchiolitis (85 patients) and mild-moderate bronchiolitis (355 patients). No difference was determined between the two groups in terms of age or sex, although weight-for-age z-scores were significantly lower in the severe bronchiolitis group compared to the mild-moderate bronchiolitis group $(\mathrm{p}<0.001)$. No significant differences were observed between the two groups in terms of birth week, cesarean delivery, receipt of mother's milk only, atopic disease, GERD, or history of admission to the NICU. However, attack numbers were significantly higher in the severe bronchiolitis group than in the mild-moderate group (Table 1).

No statistically significant difference was determined between the two groups in terms of parental histories of asthma ( $\mathrm{p}=0.240)$. No significant difference was also found between the groups in terms of maternal histories of smoking during pregnancy and paternal active smoking histories, although the proportion of mothers with active smoking histories was significantly higher in the severe bronchiolitis group (20\%) than in the mild-moderate bronchiolitis group (11.3\%) $(\mathrm{p}=0.050, \mathrm{p}=0.617$, and $\mathrm{p}=0.046$, respectively). No significant 
difference was observed between the two groups in terms of maternal education levels, but paternal education levels were lower in the severe bronchiolitis group $(\mathrm{p}=0.414$ and $\mathrm{p}=0.028$, respectively). No significant difference was also observed between the two groups in terms of place and type of residence, and type of heating employed. A history of being the only child in the home was significantly lower in the severe group than in the mild-moderate group $(\mathrm{p}=0.010)$, while the number of individuals in the household was higher in the severe group than in the mild-moderate group $(\mathrm{p}=0.011)$ (Table 2$)$.

Feeding was lower, subcostal retraction and cyanosis were more common, times between onset of symptoms and worsening of findings and presentation to hospital were shorter, oxygen saturation was lower, HFNC and intubation requirements were more frequent, and hospital stays were longer in the severe bronchiolitis group compared to the mild-moderate bronchiolitis group (Table 3).

Mean $\mathrm{Hb}$ values were $10.83 \pm 1.47 \mathrm{~g} / \mathrm{dL}$ in the severe bronchiolitis group and $11.19 \pm 1.21 \mathrm{~g} / \mathrm{dL}$ in the mildmoderate bronchiolitis group $(\mathrm{p}=0.021)$. Mean absolute neutrophil count was $5.34 \pm 4.45 / \mathrm{mm}^{3}$ in the severe bronchiolitis group and $4.38 \pm 3.32 / \mathrm{mm}^{3}$ in the mild-moderate group $(\mathrm{p}=0.004)$. CRP values were $1.74 \pm 2.78$ $\mathrm{mg} / \mathrm{dL}$ in the severe bronchiolitis group and $0.96 \pm 1.79 \mathrm{mg} / \mathrm{dL}$ in the mild-moderate group $(\mathrm{p}=0.002)$.

Each demographic, clinical, and laboratory variable of the patients included in the study was individually subjected to univariate logistic regression analysis in order to identify parameters potentially associated with the development of bronchiolitis. Accordingly, weight-for-age z-score, time between onset of symptoms and admission, time between onset of symptoms and worsening of findings, number of previous bronchiolitis attacks, history of maternal smoking during pregnancy, history of maternal active smoking, being an only child, number of individuals in the household, decreased feeding, hemoglobin levels, absolute neutrophil count, lymphocyte count, and CRP emerged as significant at the $\mathrm{p}<0.05$ level. The above parameters emerging as significant at univariate logistic regression analysis were than subjected to multivariate logistic regression analysis (backward LR model). Parameters identified at multivariate logistic regression analysis such as a low weight-for-age z-score, a short time between onset of symptoms and admission, a higher number of previous attacks, and low hemoglobin emerged as independent predictors of severe bronchiolitis development. Low weight-for-age z-score was found to increase the risk of severe bronchiolitis development 0.56 -fold (CI: 0.409 - 0.760), a short time between onset of symptoms and admission increased the risk 0.62-fold (CI: 0.519 0.735 ), previous history of frequent bronchiolitis attacks increased the risk 1.84-fold (CI: 1.135-2.968), and low hemoglobin levels increased the risk 0.72-fold (CI: $0.537-0.969)$ (Table 4).

\section{Discussion}

Identifying the factors increasing the risk of development of severe bronchiolitis in patients without chronic disease is important in terms of standardizing the frequency of follow-ups of bronchiolitis patients and hospitalization indications, and the decision to intervene early in at-risk patients. The purpose of the present study was to determine individual, familial, and environmental predictive risk factors for the development of severe bronchiolitis in healthy-appearing cases of acute bronchiolitis with no previous history of chronic disease.

In a study of children with bronchiolitis requiring mechanical ventilation, Mansbach et al. ${ }^{6}$ found that $61 \%$ of cases assessed as severe bronchiolitis and given respiratory support with CPAP or intubation were boys, and $39 \%$ were girls. Robledo-Aceves et al. ${ }^{3}$ investigated risk factors for severe bronchiolitis in the emergency department and observed that $60.5 \%$ of severe bronchiolitis cases were boys. Similarly in the present study, boys constituted $60 \%$ of the cases valuated as severe bronchiolitis, and girls $40 \%$, no statistically significant difference being observed with the mild-moderate patient group.

Robledo-Aceves et al. ${ }^{3}$ reported a mean age of 6.60 months in their cases of severe bronchiolitis, but observed no significant difference compared to the control group. Mansbach et al. ${ }^{6}$ a significantly higher mechanical ventilation requirement in the first six months, and especially in patients younger than two months, compared to the control group. In their study of risk factors for respiratory decompensation, Dadlez et al. ${ }^{8}$ reported a mean age of 4.2 months in a group developing respiratory failure and 7.2 months in a group with no respiratory failure, the difference being statistically significant. They authors also identified age less than six 
months as a significant predictor of respiratory decompensation. In the present study, the mean age of the cases with severe bronchiolitis was 6.50 months, and that of the mild-moderate bronchiolitis cases was 6.07, the difference not being statistically significant.

Dadlez et al. ${ }^{8}$ determined no statistically significant difference in weight-for-age z-scores between groups developing and not developing respiratory failure. Weight-for-age z-scores of -0.87 in cases of severe bronchiolitis and -0.30 in mild-moderate cases were determined in the present study $(\mathrm{p}<0.001)$. In addition, multivariate logistic regression analysis identified a low weight-for-age z-score as an independent predictor of development of severe bronchiolitis, increasing the risk of development 0.56 -fold.

In a study of the severity of respiratory syncytial virus (RSV) infection and breastfeeding, Nishimura et al. ${ }^{9}$ determined a more severe clinical course among non-breastfed young infants, and reported that breastfeeding exhibited a protective effect. Mansbach et al. ${ }^{6}$ determined a history of breastfeeding in $57 \%$ of cases of severe bronchiolitis and in $61 \%$ of a control group, although the difference was not statistically significant. Similarly in the present study, a history of breastfeeding only was present in $74.1 \%$ of cases in the severe bronchiolitis group, and in $75.2 \%$ of the mild-moderate group, the difference also not being statistically significant.

Semple et al. ${ }^{10}$ reported a mean gestation time of 35.8 weeks in cases requiring mechanical ventilation support compared to 38 weeks in a control group, the difference being statistically significant. Coşkun et al. ${ }^{11}$ investigated risk factors for intensive care requirements among children with bronchiolitis and determined a mean gestation period of 37.9 weeks in a group followed-up in intensive care and of 38.2 weeks in a control group, the difference not being significant. Mean gestation in the severe bronchiolitis group in the present study was 38.2 weeks, compared to 38.3 weeks in the mild-moderate bronchiolitis group. The difference was not significant $(\mathrm{p}=0.602)$.

Mansbach et al. ${ }^{6}$ reported a previous history of bronchiolitis attacks in $19 \%$ of severe bronchiolitis cases and in $23 \%$ of a control group, the difference not being significant. In the present study, a previous history of bronchiolitis attacks was observed in $36.5 \%$ of severe bronchiolitis cases, significantly higher than in mildmoderate cases at $27.1 \%(\mathrm{p}=0.004)$. At multivariate logistic regression analysis, a history of frequent previous bronchiolitis attacks emerged as an independent predictor of severe bronchiolitis development, increasing the risk 1.84-fold.

Mansbach et al. ${ }^{6}$ reported no significant difference in familial history of asthma, being observed in $32 \%$ of a severe bronchiolitis group and $31 \%$ of a control group. A family history of asthma was determined in $9.5 \%$ of the severe bronchiolitis group and $11.6 \%$ of the mild-moderate bronchiolitis group, and the difference was not significant $(\mathrm{p}=0.240)$.

Hasegawa et al. ${ }^{12}$ investigated risk factors necessitating intensive care are reported exposure to cigarette smoke in $17 \%$ of patients transferred to intensive care due to clinical worsening and in $13 \%$ of a control group. The difference was not significant. Mansbach et al. ${ }^{6}$ reported exposure to cigarette smoke in $11 \%$ of a group with severe bronchiolitis and in $13 \%$ of a control group. The difference was significant. Robledo-Aceves et al. ${ }^{3}$ described exposure to cigarette smoke as a single independent risk factor associated with severe bronchiolitis. In the present study, rates of exposure to cigarette smoke associated with active maternal smoking were $20 \%$ in the severe bronchiolitis group and $11.3 \%$ in the mild-moderate group, and the difference was statistically significant $(\mathrm{p}=0.046)$. However, exposure to cigarette smoke was not identified as an independent predictor of severe bronchiolitis development at multivariate logistic regression analysis.

Mansbach et al. ${ }^{6}$ reported an independent association between maternal smoking during pregnancy and severe bronchiolitis requiring CPAP and/or intubation. Robledo-Aceves et al. ${ }^{3}$ determined smoking during pregnancy in $7.5 \%$ of the severe bronchiolitis group and $6.7 \%$ of the mild-moderate group, the difference being insignificant. Rates of maternal smoking during pregnancy in the present study were $16.5 \%$ in the severe bronchiolitis group and $9 \%$ in the mild-moderate group. The difference was also not significant $(\mathrm{p}=0.050)$.

Coşkun et al. ${ }^{11}$ reported a higher number of siblings among a group followed-up in intensive care compared to 
a control group, although the difference was not significant. In the present study, $12.9 \%$ of severe bronchiolitis cases and $26.5 \%$ of mild-moderate cases were only children $(\mathrm{p}=0.010)$. However, this did not emerge as an independent predictor of severe bronchiolitis development. Robledo-Aceves et al. ${ }^{3}$ reported that $71.6 \%$ of a severe bronchiolitis group and $42.5 \%$ of a control group lived in crowded conditions, and that this was linked to severe bronchiolitis. The number of members of the household in the present study was higher in the severe bronchiolitis group than in the mild-moderate group $(\mathrm{p}=0.011)$. However, this did not emerge as an independent predictor of severe bronchiolitis at multivariate logistic regression analysis.

Mansbach et al. ${ }^{6}$ reported a significantly higher rate of reduced feeding in the severe bronchiolitis group, at $63 \%$, compared to $41 \%$ in the control group. They also reported an independent association between reduced feeding and severe bronchiolitis requiring mechanical ventilation. Rates of oral feeding in the present study were $76.5 \%$ in the severe bronchiolitis cases and $62 \%$ in the mild-moderate bronchiolitis cases $(\mathrm{p}=0.016)$. However, this did not emerge as an independent predictor of severe bronchiolitis at multivariate logistic regression analysis.

Semple et al. ${ }^{10}$ reported times between onset of symptoms and admission to hospital of 3.1 days in a group developing respiratory insufficiency receiving mechanical ventilation support, of 3.6 days in a group given oxygen support only, and of 4.2 days in a group not given oxygen support, although the difference was not statistically significant. DeVincenzo et al. ${ }^{13}$ reported an approximate time of four days between onset of symptoms and admission, but did not evaluate this as significant in terms of intensive care requirement and respiratory insufficiency. The relevant findings in the present study were 4.04 days in the severe bronchiolitis group and 4.90 days in the mild-moderate bronchiolitis group $(\mathrm{p}=0.017)$. A short time between onset of symptoms and admission was identified as an independent predictive parameter in the development of severe bronchiolitis, increasing the risk of severe bronchiolitis 0.62 -fold.

Hasegawa et al. ${ }^{12}$ reported similar onset durations of respiratory difficulty, one of the findings of clinical worsening, between a group requiring intensive care and another with no such requirement. In Mansbach et al.'s study ${ }^{6}, 39 \%$ of severe bronchiolitis cases experienced respiratory difficulty for less than one day before presentation, compared to $26 \%$ of the control group, and an independent association was determined with mechanical ventilation requirement. In the present study, the time elapsing between onset of symptoms and worsening of findings was 2.78 days in the sever bronchiolitis group and 4.29 days in the mild-moderate group $(\mathrm{p}<0.001)$. However, this did not emerge as an independent predictive parameter in the development of severe bronchiolitis at multivariate logistic regression analysis.

Tourniaire et al. ${ }^{14}$ investigated whether $\mathrm{Hb}$ concentrations were a factor in clinical worsening, and reported mean $\mathrm{Hb}$ values of $11.1 \mathrm{~g} / \mathrm{dL}$ in a group with severe bronchiolitis and $12 \mathrm{~g} / \mathrm{dL}$ in a control group, the difference being statistically significant. They also determined that cases Hb values lower than $10 \mathrm{~g} / \mathrm{dL}$ resulted in long-term respiratory support requirements. Mean Hb values in the present study were 10.83 $\mathrm{g} / \mathrm{dL}$ in the severe bronchiolitis group and $11.19 \mathrm{~g} / \mathrm{dL}$ in the mild-moderate group $(\mathrm{p}=0.021)$. Low Hb values also emerged as an independent predictive parameter in severe bronchiolitis development at logistic regression analysis, increasing the risk of severe bronchiolitis 0.72 -fold. We think that low $\mathrm{Hb}$ may result in worsening of the manifestation in bronchiolitis patients by reducing oxygen transport capacity.

In conclusion, we observed a higher risk of severe bronchiolitis development in individuals with a low weightfor-age z-score, with a short time elapsing between onset of symptoms and admission, with a larger number of previous attacks, and with low hemoglobin. We think that consideration and identification of these risk factors will serve as a guide to clinicians in the early determination of cases of severe bronchiolitis.

\section{References}

1. Ralston SL, Lieberthal AS, Meissner HC, et al. Clinical practice guideline: the diagnosis, management, and prevention of bronchiolitis.Pediatrics . 2014;134(5):1474-502. doi: 10.1542/peds.2015-2862.

2. Coates BM, Camarda LE, Goodman DM. Wheezing, Bronchiolitis, and Bronchitis. In: Kliegman RM, Stanton BF, St Geme JW, Schor NF. Nelson Textbook of Pediatrics. 20th ed, Philadelphia: Elsevier Saunders; 2015. p. 2044-8. 
3. Robledo-Aceves M, Moreno-Peregrina MJ, Velarde-Rivera F, et al. Risk factors for severe bronchiolitis caused by respiratory virus infections among Mexican children in an emergency department.Medicine . 2018;97(9):e0057. doi: 10.1097/MD.0000000000010057.

4. Lanari M, Prinelli F, Adorni F, et al. Risk factors for bronchiolitis hospitalization during the first year of life in a multicenter Italian birth cohort. Ital J Pediatr . 2015;41:40. doi: 10.1186/s13052-015-0149-z.

5. Lanari M, Vandini S, Adorni F, et al. Prenatal tobacco smoke exposure increases hospitalizations for bronchiolitis in infants. Respir Res . 2015;16:152. doi: 10.1186/s12931-015-0312-5.

6. Mansbach JM, Piedra PA, Stevenson MD, et al. Prospective multicenter study of children with bronchiolitis requiring mechanical ventilation.Pediatrics . 2012;130(3):e492-500. doi: 10.1542/peds.2012-0444.

7. Tahamtan A, Askari FS, Bont L, Salimi V. Disease severity in respiratory syncytial virus infection: Role of host genetic variation.Rev Med Virol. 2019;29(2):e2026. doi: 10.1002/rmv.2026.

8. Dadlez NM, Esteban-Cruciani N, Khan A, Douglas LC, Shi Y, Southern WN. Risk Factors for Respiratory Decompensation Among Healthy Infants With Bronchiolitis. Hosp Pediatr. 2017;7(9):530-535. doi: 10.1542/hpeds.2017-0034

9. Nishimura T, Suzue J, Kaji H. Breastfeeding reduces the severity of respiratory syncytial virus infection among young infants: a multi-center prospective study. Pediatr Int. 2009;51(6):812-6. doi: 10.1111/j.1442-200X.2009.02877.x.

10. Semple MG, Taylor-Robinson DC, Lane S, Smyth RL. Household tobacco smoke and admission weight predict severe bronchiolitis in infants independent of deprivation: prospective cohort study. PLoS One.2011;6(7):e22425. doi: 10.1371/journal.pone.0022425.

11. Coskun Y, Sağlam F, Mamal-Torun M, Akman İ. Risk factors for intensive care need in children with bronchiolitis: A case-control study.Turk J Pediatr. 2017;59(5):520-523. doi: 10.24953/turkjped.2017.05.003.

12. Hasegawa K, Pate BM, Mansbach JM, et al. Risk factors for requiring intensive care among children admitted to ward with bronchiolitis.Acad Pediatr. 2015;15(1):77-81. doi: 10.1016/j.acap.2014.06.008.

13. DeVincenzo JP, El Saleeby CM, Bush AJ. Respiratory syncytial virus load predicts disease severity in previously healthy infants. J Infect Dis. 2005;191(11):1861-8. doi: 10.1086/430008.

14. Tourniaire G, Milési C, Baleine J, et al. Anemia, a new severity factor in young infants with acute viral bronchiolitis? Arch Pediatr. 2018;25(3):189-193. doi: 10.1016/j.arcped.2018.02.001.

Table 1. A comparison of the groups' sociodemographic and history characteristics

\begin{tabular}{|c|c|c|c|}
\hline & $\begin{array}{l}\text { Severe bronchiolitis } \\
\text { group }(n=85)\end{array}$ & $\begin{array}{l}\text { Mild-moderate } \\
\text { bronchiolitis group } \\
(\mathbf{n}=\mathbf{3 5 5})\end{array}$ & $\mathrm{p}$ \\
\hline$\overline{\text { Sex }(\text { male } / \text { female })^{\mathrm{a}}}$ & $51 / 34$ & $226 / 129$ & 0.530 \\
\hline Age (months) $)^{b}$ & $6.50 \pm 6.06$ & $6.07 \pm 4.72$ & 0.482 \\
\hline Weight-for-age z-score ${ }^{b}$ & $-0.87 \pm 1.54$ & $-0.30 \pm 1.16$ & $<0.001 *$ \\
\hline Birth week ${ }^{\mathrm{b}}$ & $38.24 \pm 2.69(28-41)$ & $38.39 \pm 2.37(24-42)$ & 0.602 \\
\hline Cesarean delivery ${ }^{\mathrm{a}}$ & $43(50.6 \%)$ & $163(45.9 \%)$ & 0.469 \\
\hline Feeding type $\mathrm{c}^{\mathrm{c}}$ & & & 0.263 \\
\hline Mother's milk only & $63(74.1 \%)$ & $267(75.2 \%)$ & \\
\hline $\begin{array}{l}\text { Mother's milk }+ \\
\text { additional food }\end{array}$ & $19(22.4 \%)$ & $84(23.7 \%)$ & \\
\hline Formula milk only & $3(3.5 \%)$ & $4(1.1 \%)$ & \\
\hline $\begin{array}{l}\text { History of atopic } \\
\text { disease }^{c}\end{array}$ & & & 0.073 \\
\hline $\begin{array}{l}\text { Gastroesophageal } \\
\text { reflux disease }\end{array}$ & $1(1.2 \%)$ & $12(3.4 \%)$ & 0.478 \\
\hline $\begin{array}{l}\text { Hospitalization in } \\
\text { neonatal intensive care }\end{array}$ & $30(35.3 \%)$ & $89(25.1 \%)$ & 0.059 \\
\hline
\end{tabular}




\begin{tabular}{llll}
\hline & $\begin{array}{l}\text { Severe bronchiolitis } \\
\text { group }(\mathbf{n}=\mathbf{8 5})\end{array}$ & $\begin{array}{l}\text { Mild-moderate } \\
\text { bronchiolitis group } \\
(\mathbf{n}=\mathbf{3 5 5})\end{array}$ & $\mathrm{p}$ \\
\hline $\begin{array}{l}\text { Number of bronchiolitis } \\
\text { attacks }\end{array}$ & $1.59 \pm 1.02(1-5)$ & $1.34 \pm 0.64(1-4)$ & $\mathbf{0 . 0 0 4 *}$ \\
\hline
\end{tabular}

${ }^{*} \mathrm{p}<0.05$; a, chi-square test; $\mathrm{b}$, independent two sample t test; $\mathrm{c}$, chi-square and Fischer's exact test

Table 2. Comparison of the groups' family and environmental history

\begin{tabular}{|c|c|c|c|}
\hline & $\begin{array}{l}\text { Severe bronchiolitis } \\
\text { group }(n=85)\end{array}$ & $\begin{array}{l}\text { Mild-moderate } \\
\text { bronchiolitis group } \\
(\mathrm{n}=\mathbf{3 5 5})\end{array}$ & $\mathrm{p}$ \\
\hline $\begin{array}{l}\text { History of asthma in } \\
\text { the parents }{ }^{\text {a }}\end{array}$ & $8(9.5 \%)$ & $41(11.6 \%)$ & 0.240 \\
\hline $\begin{array}{l}\text { Maternal history of } \\
\text { smoking during } \\
\text { pregnancy }{ }^{a}\end{array}$ & $14(16.5 \%)$ & $32(9.0 \%)$ & 0.050 \\
\hline $\begin{array}{l}\text { Maternal history of } \\
\text { active smoking }^{\mathrm{a}}\end{array}$ & $17(20.0 \%)$ & $40(11.3 \%)$ & $0.046^{*}$ \\
\hline $\begin{array}{l}\text { Paternal history of } \\
\text { active smoking a }\end{array}$ & $52(61.2 \%)$ & $228(64.2 \%)$ & 0.617 \\
\hline $\begin{array}{l}\text { Maternal education } \\
\text { level }^{\mathrm{b}}\end{array}$ & & & 0.414 \\
\hline Illiterate & $6(7.1 \%)$ & $15(4.2 \%)$ & \\
\hline Literate & $1(1.2 \%)$ & $5(1.4 \%)$ & \\
\hline $\begin{array}{l}\text { Elementary school } \\
\text { graduate }\end{array}$ & $35(41.2 \%)$ & $119(33.5 \%)$ & \\
\hline Middle school graduate & $20(\% 23.5)$ & $112(\% 31.5)$ & \\
\hline High school graduate & $18(21.2 \%)$ & $71(20.0 \%)$ & \\
\hline University graduate & $5(5.9 \%)$ & $33(9.3 \%)$ & \\
\hline $\begin{array}{l}\text { Paternal education } \\
\text { level }^{\mathrm{b}}\end{array}$ & & & $0.028^{*}$ \\
\hline Illiterate & $4(4.7 \%)$ & $6(1.7 \%)$ & \\
\hline Literate & - & $2(0.6 \%)$ & \\
\hline $\begin{array}{l}\text { Elementary school } \\
\text { graduate }\end{array}$ & $28(32.9 \%)$ & $101(28.5 \%)$ & \\
\hline Middle school graduate & $14(16.5 \%)$ & $107(30.1 \%)$ & \\
\hline High school graduate & $28(32.9 \%)$ & $80(22.5 \%)$ & \\
\hline University graduate & $11(12.9 \%)$ & $59(16.6 \%)$ & \\
\hline $\begin{array}{l}\text { Being the family's only } \\
\text { child }^{\text {a }}\end{array}$ & $11(12.9 \%)$ & $94(26.5 \%)$ & $0.010^{*}$ \\
\hline $\begin{array}{l}\text { Number of individuals } \\
\text { in the household }\end{array}$ & $5.55 \pm 2.00(3-12)$ & $5.00 \pm 1.75(3-15)$ & $0.011 *$ \\
\hline $\begin{array}{l}\text { Place of residence } \\
(\text { urban/rural) })^{\mathrm{a}}\end{array}$ & $66 / 19$ & $27 / 84$ & 0.887 \\
\hline $\begin{array}{l}\text { Type of home } \\
\text { (self-contained } \\
\text { house/apartment) }\end{array}$ & $59 / 26$ & $228 / 127$ & 0.379 \\
\hline
\end{tabular}




\begin{tabular}{llll}
\hline & $\begin{array}{l}\text { Severe bronchiolitis } \\
\text { group }(\mathbf{n}=\mathbf{8 5})\end{array}$ & $\begin{array}{l}\text { Mild-moderate } \\
\text { bronchiolitis group } \\
(\mathbf{n = 3 5 5 )}\end{array}$ & $\mathrm{p}$ \\
\hline $\begin{array}{l}\text { Type of heating } \\
\text { (natural gas/stove) }^{\mathrm{a}}\end{array}$ & $23 / 62$ & $125 / 230$ & 0.162 \\
\hline
\end{tabular}

${ }^{*} \mathrm{p}<0.05$; a, chi-square test; $\mathrm{b}$, chi-square and Fischer's exact test; $\mathrm{c}$, independent two sample t test

Table 3. Comparison of the groups' clinical characteristics

\begin{tabular}{|c|c|c|c|}
\hline & $\begin{array}{l}\text { Severe bronchiolitis } \\
\text { group }(n=85)\end{array}$ & $\begin{array}{l}\text { Mild-moderate } \\
\text { bronchiolitis group } \\
(\mathrm{n}=355)\end{array}$ & $\mathrm{p}$ \\
\hline Decreased feeding ${ }^{\mathrm{a}}$ & $65(76.5 \%)$ & $220(62.0 \%)$ & $0.016^{*}$ \\
\hline $\begin{array}{l}\text { Time elapsed between } \\
\text { onset of symptoms and } \\
\text { admission b }\end{array}$ & $4.04 \pm 2.11(1-10)$ & $4.90 \pm 3.15(1-20)$ & $0.017^{*}$ \\
\hline $\begin{array}{l}\text { Time elapsed between } \\
\text { onset of symptoms and } \\
\text { worsening of findings b }\end{array}$ & $2.78 \pm 1.62(1-8)$ & $4.29 \pm 1.78(1-10)$ & $<0.001 *$ \\
\hline Subcostal retraction ${ }^{\mathrm{a}}$ & $81(95.3 \%)$ & $15(4.2 \%)$ & $<0.001^{*}$ \\
\hline Cyanosis $^{\mathrm{a}}$ & $38(44.7 \%)$ & $24(6.8 \%)$ & $<0.001 *$ \\
\hline Oxygen saturation ${ }^{\mathrm{b}}$ & $86.61 \pm 3.62(70-93)$ & $97.07 \pm 3.41(80-100)$ & $<0.001^{*}$ \\
\hline Oxygen requirement $^{\mathrm{c}}$ & & & $<0.001^{*}$ \\
\hline By mask & - & $40(11.3 \%)$ & \\
\hline $\mathrm{HFNC}+$ & $82(96.5 \%)$ & - & \\
\hline Intubation & $3(3.5 \%)$ & - & \\
\hline $\begin{array}{l}\text { Length of } \\
\text { hospitalization }(\text { days })^{\mathrm{b}}\end{array}$ & $7.87 \pm 3.50(3-20)$ & $4.94 \pm 2.46(1-20)$ & $<0.001^{*}$ \\
\hline
\end{tabular}

${ }^{*} \mathrm{p}<0.05$; a, chi-square test; b, independent two sample t test; c, chi-square and Fischer's exact test; + , HFNC: high-flow nasal cannula

Table 4. Determination of independent predictors of severe bronchiolitis at multivariate logistic regression analysis (backward LR model)

\begin{tabular}{llll}
\hline & Beta & OR $(\mathbf{9 5 \%}$ CI $)$ & $\mathrm{p}$ \\
\hline Weight-for-age z-score & -0.584 & $0.558(0.409-0.760)$ & $<\mathbf{0 . 0 0 1}^{*}$ \\
Time elapsed between onset of symptoms and admission & -0.482 & $0.617(0.519-0.735)$ & $<\mathbf{0 . 0 0 1}^{*}$ \\
Number of previous bronchiolitis attacks & 0.607 & $1.835(1.135-2.968)$ & $\mathbf{0 . 0 1 3}^{*}$ \\
Hemoglobin & -0.327 & $0.721(0.537-0.969)$ & $\mathbf{0 . 0 3 0 ^ { * }}$ \\
\hline
\end{tabular}

OR (95\% CI), odds ratio (95\% CI); ${ }^{*} \mathrm{p}<0.05$ 